\title{
A Study of Diversity Climate Perception in a Telecom MNC: Bhubaneswar
}

\author{
VandanaMohanty, Dr. Sujit Kumar Acharya \\ Assistant Professor International Institute Of Management Science, Pune \\ Department Of Management Studies, DDCE, Utkal University
}

\begin{abstract}
Diversity climate perception and satisfaction at the work place are distinct but related constructs, and both appear to influence employees' understanding of the work environment and their perception of Diversity. The objective of this study was to explore the employees' perceptions of the work environment and their acceptance of Diversity. A Diversity climate questionnaire was administered to a convenience sample of 75 employees from a population of 105 employees working in a Telecom Company, a MNC at Bhubaneswar. An independent sample t test was run to support the findings. The results show significant differences among investigated groups. For instance, higher education level, and age lead to a higher positive perception of diversity. It also shows a significant relationship between them.In between the study, two other diversity variables culture and language are discovered which could have taken in the study. Perception of the diversity climate helped in understanding the level of Diversity that is prevalent in the organization. This study will help in highlighting the need for more transparent and diversity-sensitive recruitment, promotion, and networking policies/practices. Our paper will contribute to the literature of Diversity Climate Perception by investigating the perception of employees on Diversity and the role that diversity will play on employees attitude and satisfaction level.
\end{abstract}

Keywords: Climate, Culture, Diversity, Language, Perception

\section{Introduction}

Organizations today are becoming increasingly aware of diversity and its influences, similarly employees today are also largely influenced by the organizational context in which they work. The employee's attitude at the workplace depends on the types of climates with which they interact. With organizations aiming to achieve better productivity through a diverse workforce, they are working on creating a diverse work environment or diversity climate which will represent the employee's perceptions of organizational events, practices, policies, and procedures specific to diversity issues.Employees' observations of their organization's policies that are related to diversity leads to a perceived diversity climate, which can be defined as a climate that fosters and maintains a multicultural workforce at one end or a climate that is hostile or indifferent toward a multicultural workforce on the other end.

According to Chin (2009), “an organization's diversity climate reflects shared employee perceptions regarding the predicted consequences of various forms of workplace harassment and discrimination. In other words, a positive organizational diversity climate will be intolerant of workplace harassment and discrimination, whereas a negative diversity climate will convey to employees that harassment and discrimination are tolerated by the organization."'The factors that compose a positive diverse conducive work environment include personal demographics, professional characteristics department structural diversity, perceptions of department conducive work environment for diversity, views of the institution's commitment to diversity, and personal experiences with diversity (Mayhew et al., 2006)

A recent study by Deollite confirmed that the perception an employee has of the organization's diversity culture is an important determinant of organizational commitment and turnover intention, and further that diversity management is important to all employees, not just minorities. In summary, a commitment to diversity can create a competitive advantage in terms of reduced rates of turnover and increased levels of commitment.

\section{Diversity Climate}

Diversity climate is broadly defined as the degree to which an organization focuses on maintaining an inclusive workplace. Recent research has provided a more narrow definition that conceptualizes diversity climate as the "degree to which a firm advocates fair human resource policies and socially integrates 
underrepresented employees". We also embrace Mckay et al's (2008) definitions in this study the factors that make up a positive diversity climate include personal demographics, professional characterstics,department structural diversity, perceptions of department climate for diversity and personal experiences with diversity. Hence a diversity climate can be created by practices, procedures and rewards in the organization and it can be evaluated in three dimensions, namely, in terms of individual, group and organizational factors.

Employee's perceptions of the diversity climate in their workplace are known to have a significant impact on their job attitudes and behavior that can be defined as the degree to which a firm advocates fair human resource policies and socially integrates under represented employees. This psychological climate exerts an impact on employee job satisfaction, involvement and performance. Owing to the feelings of satisfaction and identification engendered by diversity climateperceptions, researchers have established a significant negative association between diversity climate and turnover intention. Ellis and Sonnenfield (1994) argue that there is a relationship between a positive diversity climate, job satisfaction, and commitment to the organization. Proper diversity management can increase an employee's self esteem and feeling of non belongingness to the organization especially, if the employee is from a minority group. Although an increasing number of organizations are attempting to enhance inclusiveness of underrepresented individuals through proactive efforts to manage their diversity, they may only gain from diversity through proper management and adjustment. To effectively manage diversity, an organization must value diversity; it must have diversity, and it must change the organization to accommodate diversity and make it an integral part of the organization and create a positive Diversity Climate. To which Merrill - sands et all. (2000) suggest that it is important for organizations to constantly monitor their performance regarding diversity management through employee perceptions. According to recent findings, professionals are leaving job because of unfavorable work environments which in turn can hamper the organizational commitment that the employees show for their organizations.

\section{Literature Review}

Kossek and Zonia (1993) explored the effects of organizational and group characteristics on employee perceptions of diversity climate, which was described as the value placed by employees on efforts to promote diversity in an organization and their attitudes toward thebeneficiaries of these efforts. More specifically, diversity climates were assessed as employee perceptions of the relationship between organizational excellence and the recruitment and retention of women and minorities, their qualifications and performance, and their access toresources and rewards in comparison to others. Using a sample of faculty and academic staff at a university with a demonstrated commitment to diversity, the authors found for support the proposed dimensions of diversity climate, which emerged to explain $66 \%$ of the variance. More importantly, the results of Kossek and Zonia's (1993) study highlight workforce composition and equality as components of employees' diversity climate perceptions.

As stated previously, diversity climate is the extent that a firm promotes equal employment opportunity and inclusion Cox (1994) developed the interactional model of cultural diversity (IMCD) to describe diversity climate's effects on organizational processes. According to the IMCD, diversity climate relates to firm performance through facilitative effects on employee attitudes (e.g., organizational identification, job satisfaction) and/or achievement outcomes (e.g., job performance).This conceptualization of a mediated diversity climate $\rightarrow$ employee attitudes/achievement outcomes $\rightarrow$ firm performance pathway overlaps considerably with Kopelman et al.'s (1990) general model of organizational climate effects on firm productivity. We extend this thinking to a private sector telecom level to articulate how diversity climate, across hierarchical job levels,might influence company performance.

Mor Barak et al. (1998) discuss perceptions of diversity climate through the use of two dimensions, personal and organizational. The organizational dimension is composed of two factors, organizational inclusion, which touches on training and programs designed to include women and minorities, and organizational fairness, which include discrimination and prejudice issues. The personal dimension is composed of two factors: personal comfort with diversity and personal value for diversity

Hicks-Clarke and Iles (2000) studied diversity climates within the retail industry and the UK national health service (NHS) and what factors of diversity climate impact on managerial career and organizational attitudes and perceptions, showing the impact of climate perceptions on individual career and organizational attitudes and perceptions, such as commitment, job satisfaction, satisfaction with supervisor, career commitment, career satisfaction.

Allen et al. (2008) found that employee perceptions of diversity at the senior management level of an organization are positively related to perceptions of organizationalperformance. McKay et al. (2007) found that 
a pro-diversity climate reduced turnover intentions and increased organizational commitment for both majority and minority employees of a US national retail organization.

Hankins (2005) in his doctoral dissertation investigated the relationship between perceived organizational support, job satisfaction, and perceived sexual orientation diversity acceptance. He found that individuals reporting high diversity acceptance environments also reported higher levels of perceived organizational support and higher levels of job satisfaction

Garcia and Hoelscher (2010) reviewed the literature and found that four divergent themes are widely acknowledged when defining diversity climate. These include: Perception of degree of between group conflict and acceptance of others,Level of institutional commitment to diversity (e.g., promotion of personal and emotional safety, promotion of increased demographic representation of individuals from minority populations),Fairness (e.g., acculturation processes, lack of institutional bias), and a generalized atmosphere of respect (e.g., personal attitudes and reduction of prejudices).

To study the Diversity climate perception among employees some instruments to evaluate have also been developed. The Reaction to Diversity Inventory, developed by De Meuse and Hostager (2001), assesses the general reaction and perception of employees. This inventory is recommended if there are diversity practices or endeavor in the organization. Another instrument, the Diversity Perception Scale developed by Mor Barak et al. (1998), focuses on perceptions assuming that behavior is driven by perceptions of reality. It focuses on personal and organizational dimensions in a diversity climate and it is convenient for determining the overall diversity environment. A third instrument is the Attitudes Toward Diversity Scale of Montei et al. (1996) that comprises 30 items and focuses on co-workers, supervisors, hiring and promotion decisions (Strauss/Connerley/Ammermann, 2003: 40). A final instrument that should be mentioned is the Diversity Climate Survey developed by Robert Bean and Caroline Dillon in 2000 (Bean et al., 2001). This instrument includes 15 profile questions and 15 statements, with a 5-point Likert scale. Using three dimensions (individual, group and organizational), each with five items, information on how differences are perceived, how differences affect the work of individuals and teams, and how effectively diversity is managed is gathered. The instrument can identify affective and achievement outcomes (Bean et al., 2001).

\section{OBJECTIVES}

1. To study the variation in Diversity climate perception between male and female employees in the organization.

2. To study the variation in Diversity climate perception among less experienced and more experienced employees.

3. To study the variation in Diversity cliamate perception among the young and aged employees.

4. To study the variation in Diversity climate perception among the different education levels of the employees.

\section{HYPOTHESIS}

1. There is no significant variation in the Diversity climate as perceived by male and female employees.

2. There is no significant variation in the Diversity climate perception among the young and aged employees

3. There is no significant variation in the Diversity climate perception among the Graduate and Post Graduate or Master's degree.

4. There is no significant variation in the Diversity climate perception among the less experienced and more experienced employees.

\section{Methodology}

The study is undertaken at a leading Telecom organization. The study undertaken is exploratory in nature .From the literature review various objectives were determined and hypotheses were formulated.The data was collected from the top managers, middle level, and the lower cadre employees using self-administered questionnaires. The instrument was used to collect basic statistical facts on workforce diversity climate prevailing in the organization. This research uses predominantly a quantitative survey method, but also integrates qualitative information gathered in personal meetings.

The questionnaires consisted of two parts. Part A consisted of items on demographicinformation while Parts B consisted of items regarding Diversity Climate Perception in the organization. A total of 12 items were there in the questionnaire. A 5 Point rating scale was used to measure the questionnaire. Responses include: - 1 : 
Highly Satisfied 2: Satisfied 3: Neither satisfied nor Dissatisfied 4: Dissatisfied 5: Highly Dissatisfied.

Simple Random sampling was used in the study a total of 75 questionnaires were sent for the study out of which 66 questionnaires were fully answered. The Descriptive Statistics is represented in the Table below.

Table- 1 : Descriptive Statistics

\begin{tabular}{|l|l|l|l|}
\hline Variable & Sub category & N & $\%$ \\
\hline \multirow{5}{*}{ AGE } & $20-29$ & 46 & 69 \\
\cline { 2 - 4 } & $30-39$ & 14 & 21 \\
\cline { 2 - 4 } & Above 40 & 06 & 9 \\
\hline \multirow{2}{*}{ EDUDEAT } & Male & 39 & 60 \\
\cline { 2 - 4 } & Female & 27 & 40 \\
\hline \multirow{5}{*}{ EXPERIENCE } & Graduate & 16 & 25 \\
\cline { 2 - 4 } & Post Graduate & 47 & 72 \\
\cline { 2 - 4 } & Master & 03 & 3 \\
\hline \multirow{3}{*}{ POSITION } & More than 2 Years & 17 & 26 \\
\cline { 2 - 4 } & 3-6 Yrs & 43 & 65 \\
\cline { 2 - 4 } & 7-10 Yrs & 06 & 9 \\
\hline & Junior Level & 18 & 27 \\
\cline { 2 - 4 } & Senior Level & 26 & 40 \\
\cline { 2 - 4 } & Management Level & 22 & 33 \\
\hline
\end{tabular}

In terms of the demographic profile of the respondents it is found out that a majority of the population are young (69\%).60\% of the respondents are Male. Graduation is considered as the basic qualification for the survey. $47 \%$ of the respondents are Post Graduates and only 3\% of the respondents have completed their Master's Degree. Individuals with more than 3 years of experience are in majority whereas new members accounted for only $26 \%$ of the respondents. For many of the respondents it is their first job and many of the respondents are continuing for quite a long time. Majority of the population are from the senior level accounting for $40 \%$ and then from management level $33 \%$.

\section{Analysis}

The Quantitative data obtained was analysed using statistical methods such as mean, standard deviation,one sample t-test and independent sample t-test with the help of SPSS 20 Software.

Table 2:Group Statistics

\begin{tabular}{|c|c|c|c|c|c|}
\hline & GENDER & $\mathrm{N}$ & Mean & Std. Deviation & Std. Error Mean \\
\hline \multirow{2}{*}{$\mathrm{D}$} & FEMALE & 27 & 3.44 & .974 & .187 \\
& MALE & 39 & 3.31 & .800 & .128 \\
\hline
\end{tabular}

Table 3: Independent Samples Test

\begin{tabular}{|c|c|c|c|c|c|c|c|c|c|}
\hline & \multicolumn{2}{|c|}{$\begin{array}{c}\text { Levene's Test for } \\
\text { Equality of Variances }\end{array}$} & \multicolumn{7}{|c|}{ t-test for Equality of Means } \\
\hline & \multirow[t]{2}{*}{$\mathrm{F}$} & \multirow[t]{2}{*}{ Sig. } & \multirow[t]{2}{*}{$\mathrm{t}$} & \multirow[t]{2}{*}{$\mathrm{df}$} & \multirow[t]{2}{*}{$\begin{array}{l}\text { Sig. (2- } \\
\text { tailed) }\end{array}$} & \multirow[t]{2}{*}{$\begin{array}{c}\text { Mean } \\
\text { Differenc } \\
\mathrm{e}\end{array}$} & \multirow[t]{2}{*}{$\begin{array}{c}\text { Std. Error } \\
\text { Differenc } \\
\mathrm{e}\end{array}$} & \multicolumn{2}{|c|}{$\begin{array}{l}\text { 95\% Confidence } \\
\text { Interval of the } \\
\text { Difference }\end{array}$} \\
\hline & & & & & & & & Lower & Upper \\
\hline $\begin{array}{c}\text { Equal variances } \\
\text { assumed }\end{array}$ & 1.859 & .178 & .624 & 64 & .535 & .137 & .219 & -.301 & .574 \\
\hline
\end{tabular}

The response received from 66 respondents on the 12 items of the Diversity Climate Perception was analysed using independent sample t-test with the help of SPSS 20 software.The purpose of carrying out this test was to investigate the statistical significance of the difference between the response obtained and the hypothesized value on different dimensions of Diversity Climate Perception. In the above table the two tailed significance value is $.535(>0.05)$ it means the Null Hypothesis is rejected .Here there is not enough evidence to suggest that Diversity Climate Perception is different between the male and female respondants.

Table 4 :Group Statistics

\begin{tabular}{|c|c|c|c|c|c|}
\hline & AGE & $\mathrm{N}$ & Mean & Std. Deviation & Std. Error Mean \\
\hline \multirow{2}{*}{$\mathrm{D}$ D } & Young & 46 & 3.13 & .718 & .106 \\
& Aged & 20 & 3.90 & .968 & .216 \\
\hline
\end{tabular}


Table 5 :Independent Samples Test

\begin{tabular}{|c|c|c|c|c|c|c|c|c|c|c|}
\hline & & \multicolumn{2}{|c|}{$\begin{array}{c}\text { Levene's Test for } \\
\text { Equality of Variances }\end{array}$} & \multicolumn{7}{|c|}{ t-test for Equality of Means } \\
\hline & & \multirow[t]{2}{*}{$\mathrm{F}$} & \multirow[t]{2}{*}{ Sig. } & \multirow[t]{2}{*}{$\mathrm{t}$} & \multirow[t]{2}{*}{$\mathrm{df}$} & \multirow[t]{2}{*}{$\begin{array}{l}\text { Sig. (2- } \\
\text { tailed) }\end{array}$} & \multirow[t]{2}{*}{$\begin{array}{c}\text { Mean } \\
\text { Difference }\end{array}$} & \multirow[t]{2}{*}{$\begin{array}{l}\text { Std. Error } \\
\text { Difference }\end{array}$} & \multicolumn{2}{|c|}{$\begin{array}{l}95 \% \text { Confidence } \\
\text { Interval of the } \\
\text { Difference }\end{array}$} \\
\hline & & & & & & & & & Lower & Upper \\
\hline \multirow{2}{*}{ D } & $\begin{array}{l}\text { Equal variances } \\
\text { assumed }\end{array}$ & 6.379 & .014 & & & .001 & -.770 & .214 & -1.198 & -.341 \\
\hline & $\begin{array}{l}\text { Equal variances not } \\
\text { assumed }\end{array}$ & & & -3.194 & 28.498 & .003 & -.770 & .241 & -1.263 & -.276 \\
\hline
\end{tabular}

The above table table shows the response of the different age group of employees. The young group consists of employees from the group 20-29 and the other group consists of employees more than 30.In the above table the significance value is $.003(<0.05)$. The Null Hypothesis is rejected it means that the variability between the two groups is not the same.Both the groups differ in their perception of Diversity Climate in the organization.The older employees perceive the Diversity climate better as compared to the younger employees.

\begin{tabular}{|c|c|c|c|c|c|}
\hline \multicolumn{7}{|c|}{ Table 6 : Group Statistics } \\
\hline & EDUCATION & N & Mean & Std. Deviation & Std. Error Mean \\
\hline \multirow{2}{*}{ D } & G & 16 & 3.94 & .929 & .232 \\
& PG and M & 50 & 3.18 & .774 & .110 \\
\hline
\end{tabular}

Table 7: Independent Samples Test

\begin{tabular}{|c|c|c|c|c|c|c|c|c|c|c|}
\hline & & \multicolumn{2}{|c|}{$\begin{array}{c}\text { Levene's Test for Equality } \\
\text { of Variances }\end{array}$} & \multicolumn{7}{|c|}{ t-test for Equality of Means } \\
\hline & & \multirow[t]{2}{*}{$\mathrm{F}$} & \multirow[t]{2}{*}{ Sig. } & \multirow[t]{2}{*}{$\mathrm{t}$} & \multirow[t]{2}{*}{ df } & \multirow[t]{2}{*}{$\begin{array}{l}\text { Sig. }(2- \\
\text { tailed) }\end{array}$} & \multirow[t]{2}{*}{$\begin{array}{c}\text { Mean } \\
\text { Difference }\end{array}$} & \multirow[t]{2}{*}{$\begin{array}{l}\text { Std. Error } \\
\text { Difference }\end{array}$} & \multicolumn{2}{|c|}{$\begin{array}{c}95 \% \text { Confidence Interval } \\
\text { of the Difference }\end{array}$} \\
\hline & & & & & & & & & Lower & Upper \\
\hline & $\begin{array}{l}\text { Equal variances } \\
\text { assumed }\end{array}$ & 3.501 & .066 & & 64 & .002 & .758 & .234 & .291 & 1.224 \\
\hline & $\begin{array}{c}\text { Equal variances not } \\
\text { assumed }\end{array}$ & & & 2.951 & 22.082 & .007 & .758 & .257 & .225 & 1.290 \\
\hline
\end{tabular}

In the above table the educational qualification of the respondents is divided into two groups. One group represents the employees who are only graduates and other group represents both postgraduate and masters.In our data collection out of 66 respondents only 3 people have completed their master's degree,so inorder to get a better understanding the postgraduate and graduate are grouped together.in the above table the signicant value is $.002(<0.05)$.It shows a significant relationship.Here the null hypothesis is rejected. In this case we consider that there is a statistical significant difference between the mean of employees with graduation as qualification and between masters as the educational qualification.

\begin{tabular}{|c|c|c|c|c|c|}
\multicolumn{7}{c|}{ Table 8: Group Statistics } \\
\hline \multirow{2}{*}{$\mathrm{D}$} & EXPERIENCE & $\mathrm{N}$ & Mean & Std. Deviation & Std. Error Mean \\
\hline \multirow{2}{*}{$\mathrm{D}$} & Less & 17 & 3.35 & .862 & .209 \\
& More & 49 & 3.37 & .883 & .126 \\
\hline
\end{tabular}

Table 9: Independent Samples Test

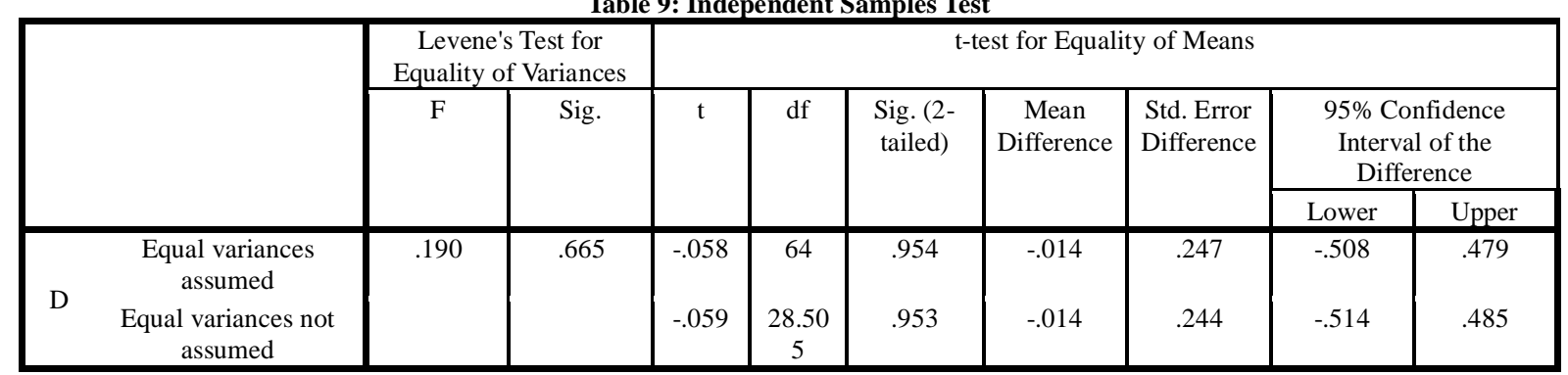

In the above table the people with less experience are the people who have more than 2 years of experience and the people with more experience are the people whose experience is more than 3 years and above. From the table the significant value is $0.954(>0.05)$. The Null hypothesis is accepted in this case .The above analysis implies that there is not sufficient evidence to conclude that less experienced employees or more experienced 
employees have difference in the perception of diversity climate.

\section{Conclusion}

In this study we investigated the issue of diversity climate perception at a leading telephone company. In the current era of intense international and multiculturaldevelopments in the Indian marketplace, determining how people in businessorganizations see "others" is imperative. Efforts in this area will providebusiness managers with ideas for human resource practices and will helpcompanies to improve their social profile in preparing for global readiness. Thestudy revealed some significant findings regarding diversity in the workplace.From our analysis, we conclude that people view diversity mainly ascultural and educational differences. Other diversity elements such as age,gender, place of birth are also viewed as sources ofdifference. In the work setting, culture, personality and education are criticalfactors that influence how people work together. The importance of the other factors can be expected to increase in2020. It is noteworthy that important differences in the social context, such asethnicity and religion, are put aside by individuals in the workplace. Genderdifference is not the main factor in organizational and social settings, which issurprising.

As expected, diversity can lead to communication problems and conflicts,whereas a lack of these problems is seen as the main advantage of ahomogeneous group. The expected benefits from diverse groups are alternativeopinions and creativity. These are essential reasons for firms to improvediversity in the workplace.The overall perception of diversity is significantly different betweenyoung and a little higher age employees. Education and age are having a significant influence on the perception ofdiversity, whereas tenure and the gender do not. Highereducation and a management role, lead to a higher positiveperception of diversity. Having a look at diversity through domestic view is the implication ofthis study for researchers where such attention is getting popular. It is alsoimportant for practitioners, managers, researchers and scholars to considerdomestic side of diversity to understand what possible attitudes will be towardforeign cultures and their members in a global world. The limitation of this research is its inclusion of limited number of employees from the state of Odisha.Thus, the results can not be generalized, however this research can be seen asan effort to give way to conduct detailed researches on diversity issue inorganizations in the future.

\section{BIBLIOGRAPHY}

[1]. Allen, R.S., Dawson, G., Wheatley, K., and White C.S. (2008). Perceived diversity and organizational performance. Employee Relations, 30(1), 20-33

[2]. Bell, M.P. Diversity in Organizations. Florence, KY: Cengage Learning, 2011.

[3]. Chin, J.L. The Psychology of Prejudice and Discrimination: A Revised and Condensed Edition. Santa Barbara, CA: Praeger/ABCCLIO, 2009.

[4]. Cox, T. Cultural Diversity in Organizations: Theory, Research \& Practice. San Francisco, California: Berrett-Koehler, 1993 .

[5]. Cox, T. H., Jr. (1993). Cultural diversity in organizations: Theory, research and practice. San Francisco, CA: Berrett-Koehler

[6]. Garcia, J.E., and Hoelscher, K.J. Managing Diversity Flashpoints in Higher Education. UK: Rowman\& Littlefield, 2010.

[7]. Hankins, K.A. (2005). The Influence of Diversity Climate on Perceived Organizational Support and Job Satisfaction. PHD dissertation. Capella University. Available http://creativityresearch.wikispaces.com/file/view/Climate_Job+satisfaction_thesis.pdf

Hegarty, W.H., and Dalton, D R. "Development and psychometric properties of the organizational diversity inventory (ODI)." Educational and Psychological Measurement, vol. 55 no. 6, pp. 1047-1052, 1995.

[8]. Hicks-Clarke, D., and Iles P. "Climate for diversity and its effects on career and organisational attitudes and perceptions." Perso nnel Review, vol. 29, no. 3, pp. $324-345,2000$.

[9]. KOSSEK, E.E./ZONIA, S.C. (1993), “Assessing Diversity Climate: A Field Study of Reactions to Employer Efforts to Promote Diversity," Journal of Organizational Behaviour, 14/1:61-81.

[10]. McKay, P.F., Avery, D.R., and Morris, M.A. "Mean racial-ethnic differences in employee sales performance: The moderating role of diversity climate.” Personnel Psychology, vol. 61, pp. 349-374, 2008.

[11]. Montei, M.S., Adams, G.A., and Eggers, M. "Validity of Scores on the Attitudes Toward Diversity Scale (ATDS)." Educational and Psychological Measurement, vol. 56, pp. 293-303, 1996

[12]. Mor Barak, M.E., Cherin, D.A., and Berkman, S. "Organizational and Personal Dimensions in Diversity Climate." The Journal of Applied Behavioural Science. vol 34, no. 1, pp. 82-104, 1998

[13]. Yeo, S. (2006). "Measuring organizational climate for diversity: a construct validation approach. Dissertation." Graduate School of The Ohio State University. Available at: http://etd.ohiolink.edu/send-pdf.cgi/Yeo\%20Sheauyuen.pdf?osu 1141677667 